\title{
Supplier evaluation and selection through DEA-AHP-GRA integrated approach- A case study
}

\author{
K.G. Durga Prasad ${ }^{a^{*}}$, K. Venkata Subbaiah ${ }^{\mathrm{b}}$ and M.V. Prasad ${ }^{\mathrm{a}}$
}

\begin{abstract}
${ }^{a}$ Department of Mechanical Engineering, G.V.P School of Engineering, Gayatri Vidya Parishad College for Degree \& P.G.Courses, Visakhapatnam, Andhra Pradesh, India

${ }^{b}$ Department of Mechanical Engineering, Andhra University, Visakhapatnam, India

C H R O N I C L E

Article history:

Received December 2, 2016

Received in revised format

December 10, 2016

Accepted April 12017

Available online

April 22017

Keywords:

Supplier evaluation

Supplier selection

Data envelopment analysis

Grey relational analysis

Analytic hierarchy process

\section{A B S T R A C T}

Supplier evaluation and selection play a vital role in establishing an effective supply chain for any firm. The supplier evaluation not only enables the firm to know the performance of suppliers, but also gives an indication of the ability of the firm itself to gain competitive advantage. The appropriate evaluation is the basis for the subsequent selection of the best supplier. This paper presents a hybrid methodology using Data Envelopment Analysis (DEA), Analytic Hierarchy Process (AHP) and Grey Relational Analysis (GRA) to evaluate suppliers and to identify the best supplier for a firm. In this work, super efficiency and cross efficiency methods of DEA are employed to determine the efficiencies and the performance scores of the suppliers respectively. On the basis of super efficiency and cross efficiency scores, the list of efficient suppliers with high performance is identified and GRA methodology is adopted to identify the best supplier. A case study is presented to demonstrate the proposed hybrid methodology.
\end{abstract}

\section{Introduction}

In the current competitive market scenario, manufacturing companies are under intense pressure to find the ways to reduce production and material costs to survive and sustain their competitive position. As the cost of raw materials and component parts constitutes the main cost of a product in most of the manufacturing companies (Ventura et al., 2013), now they are considering purchasing of raw material as a strategic function that can be used to control bottom-line costs. In high technology firms, purchased material and services represent up to $80 \%$ of total product costs (Burton, 1988; Weber, 1991). In supply chain logistics purchasing is one of the most strategic activities because it provides opportunities to reduce costs across the entire supply chain. An essential task within the purchasing process is supplier selection. As the best supplier is a good resource for a buyer in reducing such costs, the evaluation and selection of potential suppliers has become a significant component in supply chain management. A numerous evaluation and selection models for supplier selection have been reported in the supply chain literature. Most of the experts agreed that no one is the best way to evaluate and select the suppliers,

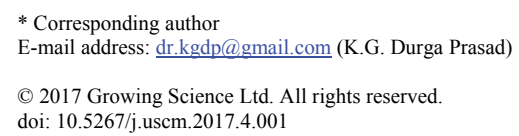


and thus organizations adopt different varieties of approaches. But the overall objectives of any approach are to reduce purchase risk and maximize overall value to the purchaser (Elanchezhian et al., 2010). Supplier evaluation is a decision making problem which includes both qualitative and quantitative factors. Dickson conducted a study that investigated the importance of supplier evaluation criteria for industrial purchasing managers. The study concluded that cost, quality and delivery performance were the most important criteria in supplier evaluation (Talluri \& Narasimhan, 2004). Over the years, a number of supplier selection criteria have been developed to meet the objectives of the respective organizations. Ho et al. (2010) reviewed the articles about supplier selection from 2000 to 2008 and they concluded that the most popular criterion considered by the decision makers is quality, followed by delivery, price/cost, manufacturing capability, service and management.

In fact, supplier evaluation and selection is a multi-criteria decision making problem. Several researchers attempted various decision making techniques to solve this issue. Timmerman (1986) proposed linear weighting models in which suppliers are rated on several criteria and these ratings are combined into a single score. Nydic and Hill (1992) used analytic hierarchy process to structure the supplier selection process. Tam and Tummala (2001) formulated AHP-based model and applied to a real case study to examine its feasibility in selecting a vendor for a telecommunication systems. Handfield et al. (2002) integrated environment issues in their supplier assessment decisions with the help of AHP. Yang and Chen (2006) proposed an integrated model by combining AHP and grey relational analysis (GRA) for evaluating potential suppliers of printed circuit boards for a note book computer firm. Yang et al., (2008) proposed integrated fuzzy multiple criteria decision making method to address the clarification between higher level criteria and lower level sub criteria within the context of vendor selection problem. Tahriri et al. (2008) formulated AHP-based supplier selection model and then it is applied to a real case study for a steel manufacturing company in Malaysia. Elanchezhian et al. (2010 a) made an attempt to select the best vendor by using Analytic Network Process (ANP) and Technique for Order Preference by Similarity to Ideal Solution (TOPSIS). Pitchipoo et al. (2012) developed a hybrid model by integrating AHP and grey relational analysis for the supplier evaluation and selection for a chemical processing industry. Punniyamoorty et al. (2012) formulated a composite model using structural equation modelling and analytic hierarchy process for the selection of suppliers.

The conventional methods that are being used for supplier evaluation such as cost ratio method, weighted-cost method, etc., are purely subjective in nature. The weighted scoring methods primarily rely on subjective judgments and views of the purchasing managers involved in the supplier evaluation process (Politis et al., 2010). The experience and contextual knowledge of purchasing staff is utilized to assign weightages arbitrarily to the supplier performance attributes. Accordingly, the final ranking of the suppliers is heavily dependent on the assignment of these weights, which are often difficult to specify in an objective manner. It is the major limitation of the weighted scoring method for supplier evaluation. Wu et al. (2007) stated that a more desirable approach will integrate managerial judgments with objective methods for improved consistency. Data Envelope Analysis (DEA) has been proven an effective method to overcome the aforesaid limitation. Narasimhan et al. (2001) proposed a methodology for effective supplier performance evaluation based on DEA. Prasad et al., (2012) developed supplier performance - efficiency score grid using DEA for identifying potential suppliers for a company. Ma et al. (2014) considered the competition between the suppliers and adopted game cross-efficiency of DEA to evaluate suppliers. Radfar and Salahi (2014) employed fuzzy DEA for supplier evaluation and Preference Ranking Organization Method for Enrichment Evaluation (PROMETHEE) model for supplier selection.

In this paper an attempt is made to propose a hybrid model by combining the methodologies of DEA, AHP and GRA. The DEA is employed to categorize potential suppliers and AHP assists to carry out the GRA methodology to identify best supplier for a firm. The overview of DEA, AHP and GRA are discussed in the following paragraphs. 


\subsection{Data Envelopment Analysis}

Data Envelopment Analysis (DEA) was developed by Charnes et al. (1978). It is a mathematical programming approach for evaluating the relative efficiency of a set of homogenous organizational units called decision making units (Malekmohammadi et al., 2011). These decision making units (DMUs) utilize multiple inputs to produce multiple outputs and their efficiency is measured by the ratio of multiple outputs to multiple inputs. DEA measure the relative productivity of a DMU by comparing it with other homogeneous units transforming the same group of measurable positive inputs into the same types of measurable positive outputs (Sepehrdoust, 2011). DEA measure has been used to evaluate and compare educational departments, health care sector, agricultural production, banking, armed forces, sports, market research transportation sector etc. In the present days, the DEA approach is extended to supply chain management issues. There are several ranking methods in DEA. The super efficiency method was developed by Anderson and Peterson (Ebadi, 2012). This method can be used in ranking the performance of efficient DMUs. The DMU being evaluated is removed from the constraint set thereby allowing its efficiency score to exceed a value of 1.00 . The efficiency score in the presence of multiple input and output factors is obtained by the computing the ratio of weighted sum of outputs to the weighted sum of inputs. The DMUs are ranked in accordance with the efficiency scores. In the year 1986, the cross efficiency evaluation method was first introduced by Sexton et.al. (Adler et al., 2002).The cross-efficiency evaluation requests each DMU not only to be self-evaluated but also to be peer-evaluated. In other words, a cross-efficiency matrix is constructed where each DMU evaluated by $n$ efficiency ratios using weight sets obtained from evaluation of the other DMUs. The average of these ratios is called average cross efficiency ratio which can be used for performance ordering (Zohrehbandian \& Gavgani, 2013). In the present work, super efficiency method is used to rank the efficient suppliers whereas cross efficiency method is employed to rank the performance of the suppliers.

\subsection{Analytic Hierarchy Process}

The Analytic Hierarchy Process (AHP) is a multi-criteria decision-making method developed by Saaty. It aims at quantifying relative priorities for a given set of alternatives on a ratio scale, based on the judgment of the decision-maker, and stresses the importance of the intuitive judgments of a decision maker as well as the consistency of the comparison of alternatives in the decision-making process (AlHarbi, 2001). AHP methodology for decision-making involves four main steps such as setup the pairwise comparison matrix, perform pair-wise comparisons of all the elements, estimation of eigen values of the matrix and checking the consistency of pair-wise judgments (Subbaiah et al., 2011). In the present work the AHP is employed to obtain the priority structure of supplier selection attributes which is further utilized in determining the grey relational grades of suppliers.

\subsection{Grey Relational Analysis}

In the year 1982, Prof. Deng Julong founded the grey system theory. Since then, it has been widely used in many fields such as agriculture, electric power, IT, transportation, economics, management, etc. The Grey system theory works on unascertained problems which have little research data and poor information (Wei \& Jun-fu, 2011). Many kinds of systems, which exist in human society and nature, are classified into three types "white system, black system, and grey system". A system whose information is completely clear is called a white system. A system whose information is not clear at all is called a black system (a black box). And a system whose information is partly clear or partly unclear is called a grey system. The meaning of 'grey' can be expressed as the characteristic between black and white. The purpose of the 'grey' system and its applications is to bridge the gap between 'black' and 'white'. In fact, incomplete information is the basic characteristic of the problems considered in grey systems theory (Madhuri \& Chandulal, 2010). GRA has advantages over statistical analysis, which requires much data and a typical model for the data distribution. GRA requires less data and can analyze 
many factors, which can overcome the disadvantages of the statistics method. It is an important approach of grey system theory in the application of determining a set of alternatives in terms of decision attributes. The calculations in GRA are simple and straight forward, calculations are based on original data and also it is considered to be one of the best methods to make decisions in the business environment (Samvedi et al., 2012). In this work, GRA is employed along with AHP to resolve the uncertainty in selecting the best supplier in the cluster of efficient and high performance suppliers. The proposed hybrid methodology for selecting best supplier for a firm is discussed in the next paragraph.

\section{Methodology}

Supplier selection is a multi-criterion decision making problem. In order to solve the problem a hybrid decision model is developed by using DEA, AHP and GRA. The schematic representation of the proposed model is shown in Fig.1.

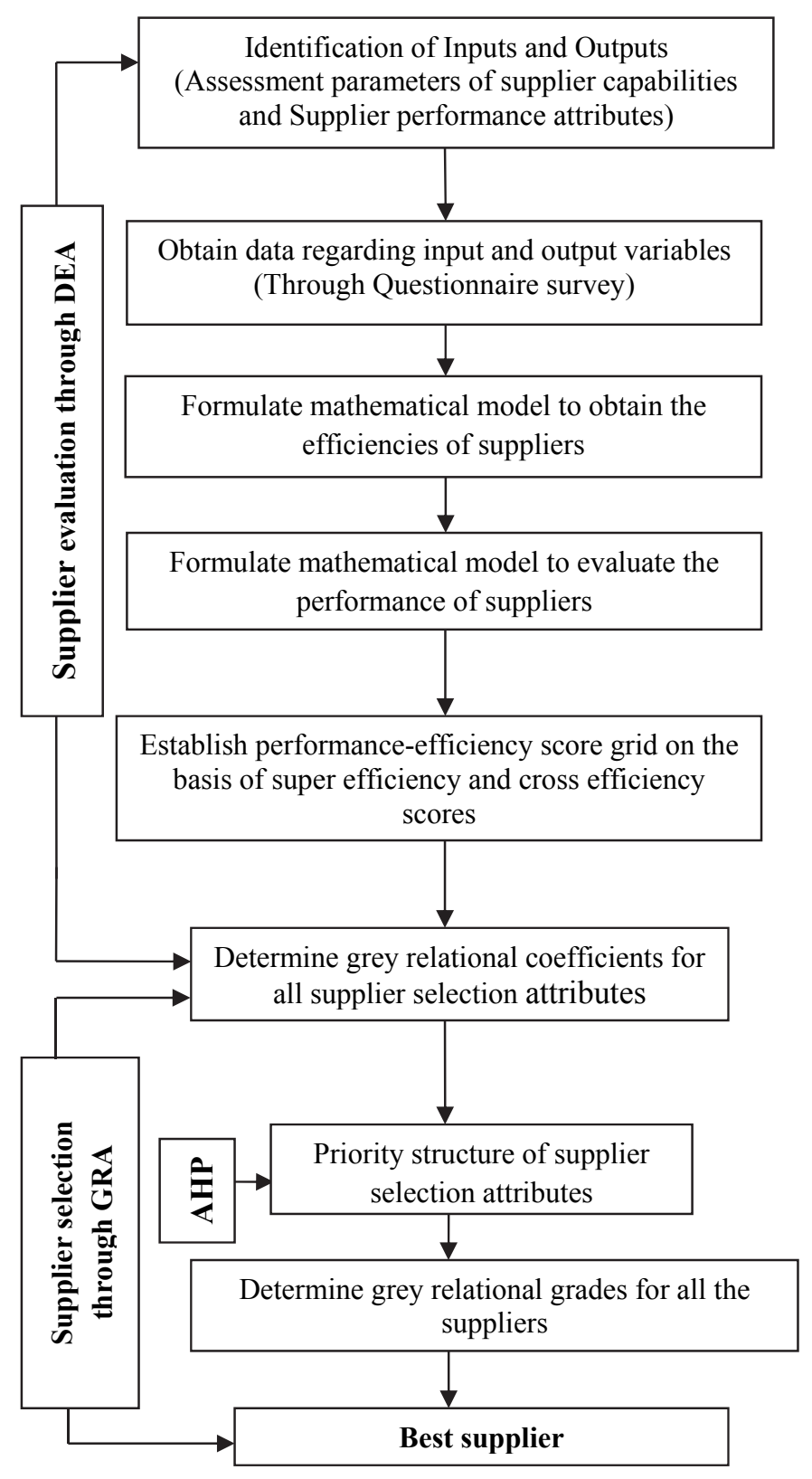

Fig. 1. The DEA, AHP, GRA Hybrid methodology for supplier selection 
The step by step procedure to carry out the methodology is discussed below:

\section{Step1: Identification of inputs and outputs}

Identify the inputs and outputs that are strategically important or critical to the buyer. The inputs and outputs are used as the selection criteria for the suppliers. Input variables are the assessment parameters of supplier capabilities (comprising the input dimensions of DEA) and the output variables reflect the supplier performance attributes (comprising the output dimension of DEA). In the process of data acquisition, the input and output dimensions to be utilized in the DEA model are defined through focus group discussions. The focus group includes managers of the different departments of the company. The specific product line to be examined was selected in the initial meetings. In the subsequent meetings, specific input and output dimensions to be used in the analysis were discussed.

\section{Step 2: Obtain the data regarding input and output variables}

The data pertaining to input variables is obtained through questionnaire survey. A questionnaire is developed by the management of the company to assess supplier capability parameters. The questionnaire is known as Supplier Capability Questionnaire. The questionnaires are distributed to various suppliers of the company to obtain their responses. In order to obtain the responses regarding output variables, Supplier Performance Assessment Questionnaire is prepared and administered to the purchasing staff of the company.

\section{Step 3: Formulation of mathematical model to obtain the efficiencies of suppliers}

A mathematical model is formulated through DEA using super efficiency method, which is given below.

Objective function: Maximize $Z=\sum_{k=1}^{s} v_{k} y_{k p}$

Subjected to constraints:

$$
\begin{aligned}
& \sum_{k=1}^{s} v_{k} y_{k i}-\sum_{j=1}^{m} u_{j} x_{j i} \leq 0 \quad \forall i \neq p \\
& \sum_{j=1}^{m} u_{j} x_{j p}=1 \\
& v_{k}, u_{j} \geq 0 \quad \forall k, j
\end{aligned}
$$

where

$i=$ Number of DMUs (suppliers); $p=$ DMU (supplier) being evaluated

$j=$ Inputs $(1$ to $m), k=$ Outputs $(1$ to $s)$,

$y_{k i}=$ amount of input $j$ utilized by supplier $i$,

$x_{j i}=$ amount of output $k$ produced by supplier $i$,

$v k=$ weight given to output $k$,

$u_{j}=$ weight given to input $j$.

\section{Step 4: Formulation of mathematical model to evaluate the performance of the suppliers}

A mathematical model is formulated through DEA using cross efficiency method, which given below.

Objective function: Maximize $Z=\sum_{k=1}^{s}\left[v_{k} \sum_{i \neq p}^{s} y_{k i}\right]$

Subject to constraints:

$$
\sum_{j=1}^{m}\left[u_{j} \sum_{i \neq p}^{s} x_{j i}\right]=1
$$




$$
\begin{aligned}
& \sum_{k=1}^{s 74} v_{k} y_{k i}-\sum_{j=1}^{m} u_{j} x_{j i} \leq 0 \quad \forall i \neq p \\
& \sum_{k=1}^{s} v_{k} y_{k p}-\theta_{p} \sum_{j=1}^{m} u_{j} x_{j p}=0 \quad v_{k}, u_{j} \geq 0 \quad \forall k, j
\end{aligned}
$$

where $\theta_{p}=$ Relative efficiency score of DMU $p$

\section{Step 5: Determination of efficiency scores of suppliers using super efficiency and cross efficiency methods}

The efficiency of each supplier can be computed by determining the ratio of the weighted sum of outputs to weighted sum of inputs. Super Efficiency indicates the extent to which the efficient suppliers exceed the efficient frontier formed by other efficient suppliers. Cross efficiency provides the information on the performance of a particular DMU with the optimal DEA weights of other DMUs. In both these methods, the efficiency of DMUs is determined by using the ratio of weighted sum of outputs to the weighted sum of inputs.

\section{Step 6: Categorization of suppliers on the basis of super efficiency and cross efficiency values}

The super efficiency and cross efficiency values help to examine the supplier capability under the categories such as High Performance and Inefficient (HI), High Performance and Efficient (HE), Low Performance and Inefficient (LI) and Low Performance and Efficient (LE). The suppliers under the category HE possesses star performance. These suppliers are the type of suppliers with whom company needs to develop a long-term relationship. The LI suppliers are candidates for pruning. The LE suppliers are the candidates need to be further developed. Finally, the potential long-term risk is associated with the HI suppliers. Even though, they are performing satisfactorily now, most likely they do not have a structure and organizational capabilities that can sustain performance in the near future.

\section{Step 7: Calculate the grey relational coefficient for supplier selection attributes}

First of all generate the referential series of $x_{0}$

$x_{0}=\left(x_{0}(1), x_{0}(2), \ldots \ldots x_{0}(j) \ldots, x_{0}(n)\right)$, in which $x_{i}$ is the compared series of $\left(x_{i}(1), x_{i}(2), \ldots . x_{i}(j) \ldots, x_{i}(n)\right)$, where $i=1,2 \ldots, \mathrm{m}$. Then normalize the data set by treating the series data set using the following three types: 'larger -is -better', 'smaller-is-better' and 'nominal-is-best'.

For 'larger-is-better' data transformation, $x_{i}(j)$ can be transformed into $x_{i}^{*}(j)$. The $x_{i}^{*}(j)$ can be calculated by using $x_{i}^{*}(j)=\frac{x_{i}(j)-\min x_{i}(j)}{\max x_{i}(j)-\min x_{i}(j)}$

For 'smaller-is-better' data transformation, $x_{i}(j)$ can be transformed into $x_{i}^{*}(j)$. The $x_{i}{ }^{*}(j)$ can be calculated by using

$x_{i}^{*}(j)=\frac{\max x_{i}(j)-x_{i}(j)}{\max x_{i}(j)-\min x_{i}(j)}$

where $\max x_{i}(j)$ and $\min x_{i}(j)$ represents the maximum and minimum values of entity $j$.

Now the grey relational coefficient for each supplier selection attribute $\gamma_{0 i}(j)$ is computed by using the following equation

$\gamma_{0 i}(j)=\frac{\Delta \min +\rho \Delta \max }{\Delta_{0 i}(j)+\rho \Delta \max }$

where $\Delta_{\min }=\min \min \Delta_{0 i}(j)$, 
$\Delta_{\max }=\max \max \Delta_{0 i}(j)$,

$\Delta_{0 i}(j)=$ absolute value of the difference between $x_{0}{ }^{*}$ and $x_{i}{ }^{*}$ at the point of $j$ and

$\rho=$ distinguished coefficient $(\rho \in[0,1])$.

\section{Step 8: Determine the priority structure of supplier selection attributes using AHP}

The AHP can be employed to obtain the weightages for the attributes. The procedure for the application of AHP is as follows.

(i) Establish pair-wise comparison matrix:

Setup the pair-wise comparison matrix of order $n \times n$ consists of $n$ elements (requirements) in the rows and columns whose priorities are to be determined.

(ii) Perform pair-wise comparisons of all the elements:

Saaty's fundamental scale of absolute numbers (Tsinidou et al., 2010) is used to perform pair-wise comparison between the elements. This comparison scale enables the decision-maker to incorporate experience and knowledge intuitively and indicate how many times an element dominates another with respect to the criterion. The decision-maker can express his preference between each pair of elements verbally as equally preferred, moderately preferred, strongly preferred, very strongly preferred and extremely preferred. These descriptive preferences would then be translated into numerical values 1, 3 , 5, 7, 9 respectively, with 2, 4, 6 and 8 as intermediate values for comparisons between two successive judgments. Reciprocals of these values are used for the corresponding transposed judgments. For a matrix of order $n, n(n-1) / 2$ comparisons are required. After the pair-wise comparisons are completed, proceed for the next step to estimate the Eigen values of the matrix.

(iii) Estimate the Eigen values of the matrix:

Averaging over normalized columns method proposed by Thomas Saaty is used to estimate the eigen values. In this method, first add the values in each column of the pair-wise comparison matrix and then divide each element in a column by the sum of its respective column. The resultant matrix is termed as the normalized pair-wise comparison matrix. Finally obtain the sum total of the elements in each row of the normalized pair-wise comparison matrix and divide the sum total with the number of elements. The result of this computation is referred to as the priority matrix and is an estimation of the Eigen values of the matrix.

(iv) Check the consistency of pair-wise judgments:

In order to verify the consistency of the pair-wise comparison matrix, Saaty proposed consistency index (CI) and consistency ratio (CR). The CI and CR are defined as follows.

$\mathrm{CI}=\frac{\lambda_{\max }-n}{n-1}$ and $\mathrm{CR}=\frac{\mathrm{CI}}{\mathrm{RI}}$

where $\lambda_{\max }=$ maximum principal Eigen value of the comparison matrix

$n=$ number of elements (order of the pair-wise comparison matrix)

The value of $\lambda_{\max }$ is obtained by first multiplying the pair-wise comparison matrix with the priority matrix. Then divide the first element of the resulting matrix by the first element of the priority matrix, the second element of the resulting matrix by the second element in the priority matrix, and so on. A single column matrix is obtained and the average of the elements of the matrix gives the value of $\lambda_{\max }$. The RI in the above equation represents the average consistency index for numerous random entries of same-order reciprocal matrices. If $\mathrm{CR} \leq 0.1$, then the estimate is accepted; otherwise, a new comparison matrix is solicited until $\mathrm{CR} \leq 0.1$ (Chang et al., 2007). 
Step 9: Determine the grey relational grades $\left(\Gamma_{0 i}\right)$ for all the suppliers

The grey relational grades for all the suppliers are computed by using the following equation.

$\Gamma_{o i}=\sum_{j=1}^{n}\left(w_{i}(j) \times \gamma_{o i}(j)\right)$

Where $w_{i}(j)=$ Weights of the supplier selection attributes

\section{Step 10: Identify the best supplier}

According to GRA, the supplier with higher grey relational grade indicates the best supplier. The methodology is exhibited through a case study which is presented in the following section.

\section{Case Study}

In order to demonstrate the proposed methodology, a case study has been under taken in an integrated steel plant located in southern India. The plant was commissioned in 1992 with a capacity to produce 3 million tons per annum of liquid steel. Steel bar rolling is one of the important processes to obtain steel bars in desired dimensions. The rolling process starts from charging billet into re-heating furnace continuously and then discharging hot billet to the rolling mill train. Then rolls reduce the billet through rolling stand until it reaches the required size. During the emerging of the billet from the roll mill, guide rollers serve to control the direction of the billet leaving the roll after rolling. The guide rollers prevent the deviation of the billet from the desired direction. In all the rolling mills, one of the essential parts are the guide rollers. The repair and maintenance of guide rollers are carried in Roll shop and Repair shop (RS\&RS). To ensure appropriate production schedule, the RS\& RS should identify the reliable suppliers for guide rollers. The study is focused on evaluation and selection of suppliers who supply guide rollers to the company. The company requires about 3,600 guide rollers annually to replace the repaired one (worn out guide rollers). Every year the company needs to spend lakhs of rupees on purchase of various guide rollers from their suppliers. Particularly, there are 16 suppliers for supplying T160Cr12IS1752-56-HRC guide rollers located nearer to the company. There are certain complaints pertaining to quality and delivery for these guide rollers on the part of the suppliers. The purchase personnel have to identify the best supplier to avoid the issues of inferior quality and improper delivery schedules. In order to identify the best supplier of guide rollers for the case company, the proposed methodology is adopted.

The assessment parameters of supplier capabilities (Input parameters of DEA) and the supplier performance attributes (output parameters of DEA) are identified through the discussions made with the managerial team of RS\& RS and the persons of purchasing department. The outcome of the discussions leads to identify six input parameters and five output parameters which are shown in Table 1.

\section{Table 1}

Inputs and outputs for the selection criteria of supplier evaluation

\begin{tabular}{ll}
\multicolumn{1}{c}{ Input parameters } & \multicolumn{1}{c}{$\begin{array}{c}\text { Output parameters } \\
\text { (Supplier performance attributes ) }\end{array}$} \\
\hline Quality management practices and systems (QMPS) & Quality \\
Documentation and self-audit (DSA) & Price \\
Freight capability (FC) & Delivery \\
Cost reduction capability (CRC) & Cost reduction performance (CRP) \\
Reliability (RE) & Service \\
Management Capability of the firm (MCF) & \\
\hline
\end{tabular}

In order to assess the supplier capability parameters (inputs) and supplier performance attributes (outputs) questionnaires are developed and they are finalized in consultation with the managerial team of the purchase department of the case company. After reviewing the questionnaires by the purchase 
management, the supplier capability assessment questionnaires are distributed to the 16 existing suppliers with a view to obtaining their responses. In this paper the suppliers are coded as S1, S2, S3,...S16 with a view to maintaining anonymity. In order to obtain the responses regarding output variables, supplier performance assessment questionnaires are administered to the purchasing personnel of the company. The response data obtained through questionnaire survey are shown in Table 2.

Table 2

Data for input and output variables (scores)

\begin{tabular}{|c|c|c|c|c|c|c|c|c|c|c|c|}
\hline \multirow{2}{*}{ 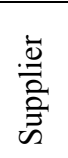 } & \multicolumn{6}{|c|}{ Input scores $\left(u_{j i}\right) ; j=1 \ldots 6, i=1 \ldots 16$} & \multicolumn{5}{|c|}{ Output scores $\left(v_{\mathrm{ki}}\right) ; k=1 \ldots 5, i=1 \ldots 16$} \\
\hline & QMPS & DSA & $\mathrm{FC}$ & $\mathrm{CRC}$ & $\mathrm{RE}$ & $\mathrm{MCF}$ & Quality & Price & Delivery & CRP & Service \\
\hline S1 & 0.25 & 0.75 & 0.33 & 0.50 & 0.00 & 1.00 & 0.25 & 1.00 & 0.20 & 0.00 & 0.33 \\
\hline S2 & 0.75 & 1.00 & 0.66 & 0.25 & 1.00 & 0.00 & 1.00 & 0.25 & 0.00 & 0.75 & 0.00 \\
\hline S3 & 0.00 & 0.25 & 1.00 & 0.75 & 0.33 & 0.66 & 0.25 & 0.50 & 0.00 & 1.00 & 1.00 \\
\hline S4 & 1.00 & 0.00 & 0.00 & 1.00 & 0.66 & 0.33 & 0.50 & 0.00 & 1.00 & 0.50 & 0.66 \\
\hline S5 & 0.50 & 0.25 & 0.33 & 0.50 & 0.00 & 1.00 & 1.00 & 0.25 & 0.50 & 0.25 & 1.00 \\
\hline S6 & 1.00 & 0.25 & 0.66 & 0.50 & 0.33 & 0.00 & 0.00 & 0.75 & 0.25 & 0.00 & 0.33 \\
\hline S7 & 0.75 & 0.75 & 0.33 & 1.00 & 0.00 & 1.00 & 0.50 & 1.00 & 0.50 & 1.00 & 0.00 \\
\hline S8 & 0.50 & 0.25 & 0.66 & 0.25 & 0.33 & 0.66 & 0.25 & 0.00 & 0.75 & 0.25 & 1.00 \\
\hline S9 & 1.00 & 0.00 & 0.66 & 1.00 & 0.66 & 1.00 & 0.00 & 0.25 & 1.00 & 0.00 & 0.00 \\
\hline $\mathrm{S} 10$ & 0.00 & 0.25 & 0.33 & 0.50 & 0.66 & 0.33 & 1.00 & 0.50 & 0.00 & 0.50 & 0.33 \\
\hline S11 & 0.75 & 0.00 & 1.00 & 0.25 & 0.33 & 1.00 & 0.25 & 0.00 & 0.25 & 0.75 & 0.66 \\
\hline $\mathrm{S} 12$ & 0.25 & 0.75 & 1.00 & 0.50 & 0.66 & 0.33 & 0.50 & 1.00 & 0.50 & 1.00 & 1.00 \\
\hline $\mathrm{S} 13$ & 0.50 & 0.00 & 1.00 & 0.25 & 0.33 & 1.00 & 1.00 & 0.75 & 0.25 & 0.00 & 0.00 \\
\hline S14 & 1.00 & 0.75 & 0.66 & 0.50 & 1.00 & 0.00 & 0.75 & 0.25 & 1.00 & 1.00 & 0.33 \\
\hline S15 & 0.00 & 0.25 & 0.33 & 1.00 & 0.33 & 0.66 & 0.25 & 0.50 & 0.00 & 0.00 & 0.66 \\
\hline $\mathrm{S} 16$ & 0.00 & 0.75 & 1.00 & 0.00 & 0.66 & 1.00 & 0.75 & 1.00 & 0.00 & 0.50 & 0.33 \\
\hline
\end{tabular}

In order to compute super efficiency and cross efficiency values for a supplier, it is required to know the amounts of inputs utilized and the amounts of outputs obtained corresponding to the supplier. The amounts of inputs and outputs are obtained by solving the mathematical models discussed in step 3 and step 4 of the methodology section. The values of inputs and outputs for determining the super efficiency and cross efficiency values for supplier $\mathrm{S} 1$ are computed by solving the mathematical models of DEA are summarized in Table 3.

\section{Table 3}

Amounts utilized and produced for Supplier S1 to calculate super efficiency and cross efficiency scores

\begin{tabular}{|c|c|c|c|c|c|c|c|}
\hline \multicolumn{4}{|c|}{ Data for determining super efficiency scores } & \multicolumn{4}{|c|}{ Data for determining cross efficiency scores } \\
\hline $\begin{array}{c}\text { Input } \\
\text { variables }\end{array}$ & $\begin{array}{c}\text { Amount } \\
\text { utilized }\end{array}$ & $\begin{array}{c}\text { Output } \\
\text { variables }\end{array}$ & $\begin{array}{l}\text { Amount } \\
\text { produced }\end{array}$ & $\begin{array}{c}\text { Input } \\
\text { variables }\end{array}$ & $\begin{array}{l}\text { Amount } \\
\text { utilized }\end{array}$ & $\begin{array}{c}\text { Output } \\
\text { variables }\end{array}$ & $\begin{array}{l}\text { Amount } \\
\text { produced }\end{array}$ \\
\hline QMPS $\left(y_{1}\right)$ & 0.6772 & Quality $\left(x_{1}\right)$ & 0.0678 & QMPS $\left(y_{1}\right)$ & 2.3362 & Quality $\left(x_{1}\right)$ & 2.1617 \\
\hline $\operatorname{DSA}\left(y_{2}\right)$ & 0.9935 & Price $\left(x_{2}\right)$ & 1.2352 & $\operatorname{DSA}\left(y_{2}\right)$ & 0.7601 & $\operatorname{Price}\left(x_{2}\right)$ & 0.5429 \\
\hline $\mathrm{FC}\left(y_{3}\right)$ & 0.9168 & $\operatorname{Delivery}\left(x_{3}\right)$ & 1.5200 & $\mathrm{FC}\left(y_{3}\right)$ & 2.8599 & $\operatorname{Delivery}\left(x_{3}\right)$ & 1.0064 \\
\hline $\operatorname{CRC}\left(y_{4}\right)$ & 0.5464 & $\operatorname{CRP}\left(x_{4}\right)$ & 1.3494 & $\operatorname{CRC}\left(y_{4}\right)$ & 1.3650 & $\operatorname{CRP}\left(x_{4}\right)$ & 1.9954 \\
\hline $\mathrm{RE}\left(y_{5}\right)$ & 0.0000 & Sorvice $(x)$ & 00024 & $\mathrm{RE}\left(y_{5}\right)$ & 3.1850 & Sorrvico $(x)$ & 02840 \\
\hline $\operatorname{MCF}\left(y_{6}\right)$ & 0.0000 & Service $\left(x_{5}\right)$ & 0.0024 & $\operatorname{MCF}\left(y_{6}\right)$ & 2.6159 & service $\left(x_{5}\right)$ & 0.2840 \\
\hline
\end{tabular}

The computations of super efficiency and cross efficiency values for supplier S1are discussed below.

$$
\begin{aligned}
& \text { Super Efficiency }=\frac{\left[\left(v_{1} \times x_{1}\right)+\left(v_{2} \times x_{2}\right)+\left(v_{3} \times x_{3}\right)+\left(v_{4} \times x_{4}\right)+\left(v_{5} \times x_{5}\right)\right]}{\left[\left(u_{1} \times y_{1}\right)+\left(u_{2} \times y_{2}\right)+\left(u_{3} \times y_{3}\right)+\left(u_{4} \times y_{4}\right)+\left(u_{5} \times y_{5}\right)+\left(u_{6} \times y_{6}\right)\right]} \\
& \frac{[(0.25 \times 0.0678)+(1.0 \times 1.2352)+(0.2 \times 1.52)+(0.00 \times 1.3494)+(0.33 \times 0.0024)]}{[(0.25 \times 0.6772)+(0.75 \times 0.9935)+(0.33 \times 0.9168)+(0.5 \times 0.5464)+(0.0 \times 0.0)+(1.0 \times 0.0)]}=1.03
\end{aligned}
$$




$$
\begin{aligned}
& \text { Cross Efficiency }=\frac{\left(x_{1}+x_{2}+x_{3}+x_{4}+x_{5}\right)\left[v_{1}+v_{2}+v_{3}+v_{4}+v_{5}\right]}{\left(y_{1}+y_{2}+y_{3}+y_{4}+y_{5}+y_{6}\right)\left[u_{1}+u_{2}+u_{3}+u_{4}+u_{5}+u_{6}\right]} \\
& =\frac{(2.1617+0.5429+1.0064+1.9954+0.2820)[0.25+1.00+0.20+0.00+0.33]}{(2.3362+0.7601+2.8599+1.3650+3.1850+2.6159)[0.25+0.75+0.33+0.50+0.00+1.00]}=0.2864
\end{aligned}
$$

In the same way, the super efficiency and cross efficiency for the remaining 15 suppliers are computed. All the suppliers are categorized and shown in Table 4 on the basis of their super efficiency and cross efficiency values.

\section{Table 4}

Super efficiency and cross efficiency values for all the suppliers

\begin{tabular}{cccc}
\hline Supplier & Super Efficiency & Cross Efficiency & Category of suppliers \\
\hline S1 & 1.03 & 0.2864 & LI \\
S2 & 0.64 & 0.2079 & LI \\
S3 & 1.08 & 0.5817 & HE \\
S4 & 3.98 & 0.5085 & HE \\
S5 & 3.05 & 0.4424 & LI \\
S6 & 1.20 & 0.1847 & LI \\
S7 & 1.68 & 0.5941 & HE \\
S8 & 2.70 & 0.5230 & HE \\
S9 & 0.86 & 0.1100 & LI \\
S10 & 1.68 & 0.2941 & LI \\
S11 & 0.66 & 0.3800 & LI \\
S12 & 1.14 & 0.5580 & HE \\
S13 & 0.70 & 0.2400 & LI \\
S14 & 1.99 & 0.6200 & HE \\
S15 & 1.26 & 0.2000 & LI \\
S16 & 0.40 & 0.2800 & LI \\
\hline
\end{tabular}

The suppliers under the category HE possesses star performance. These suppliers are the type of suppliers with whom company needs to develop a long-term relationship. The LI suppliers are candidates for pruning (Narasimham et al., 2001). The suppliers under HE category are S3, S4, S7, S8, S12 and S14. These six suppliers are the most suitable for the firm as they are efficient and having high performance. In order to identify the best supplier among these six suppliers GRA approach has been adopted.

\subsection{Application of GRA methodology to identify best supplier}

The GRA methodology consists of various steps such as generation of the data set of referential series, calculation of the grey relational coefficient for each supplier selection attributes, obtaining the weightages for the supplier selection attributes and then determining the degree of the grey relational grade for all the six suppliers.

(i) Generation of the data set of referential series: The qualitative and quantitative data of six potential suppliers is summarized and presented in the Table 5.

\section{Table 5}

Data on output variables for all the potential suppliers

\begin{tabular}{lccccc}
\hline Supplier & Quality & Price & Delivery & CRP & Service \\
\hline S3 & 0.25 & 0.50 & 0.00 & 1.00 & 1.00 \\
S4 & 0.50 & 0.00 & 1.00 & 0.50 & 0.66 \\
S7 & 0.50 & 1.00 & 0.50 & 1.00 & 0.00 \\
S8 & 0.25 & 0.00 & 0.75 & 0.25 & 1.00 \\
S12 & 0.50 & 1.00 & 0.50 & 1.00 & 1.00 \\
S14 & 0.75 & 0.25 & 1.00 & 1.00 & 0.33 \\
\hline
\end{tabular}


The data shown in Table 5 is transformed to normalized data as discussed in section 2 and is summarized in the Table 6.

Table 6

Normalized Data for all the potential suppliers

\begin{tabular}{lccccc}
\hline Supplier & Quality & Price & Delivery & CRP & Service \\
\hline S3 & 0.00 & 0.50 & 1.00 & 1.00 & 1.00 \\
S4 & 0.50 & 1.00 & 0.00 & 0.33 & 0.66 \\
S7 & 0.50 & 0.00 & 0.50 & 1.00 & 0.00 \\
S8 & 0.00 & 1.00 & 0.25 & 0.00 & 1.00 \\
S12 & 0.50 & 0.00 & 0.50 & 1.00 & 1.00 \\
S14 & 1.00 & 0.75 & 0.00 & 1.00 & 0.33 \\
\hline
\end{tabular}

The referential series $\left(x_{0}^{*}\right)$ is formed from the optimum values from each column of the matrix of normalized data.

$x_{0}^{*}=(1,0,0,1,1)$

(ii) Calculation of grey relational coefficient $\gamma_{0 i}(j)$

The grey relational coefficients (GRC) for all supplier selection attributes for supplier S3 are computed as discussed in step 8 of the section 2 .

With reference to supplier S3:

For quality: $\gamma_{0}(1)=\frac{0+0.5 \times 1}{(1-0)+0.5}=0.33$ For price: $\gamma_{0}(2)=\frac{0+0.5 \times 1}{(1-0.5)+0.5}=0.50$ For delivery: $\gamma_{0}(3)=\frac{0+0.5 \times 1}{(1-1)+0.5}=1.00$

For cost reduction performance: $\gamma_{0}(4)=\frac{0+0.5 \times 1}{(1-1)+0.5}=1.00$ For Service: $\gamma_{0}(3)=\frac{0+0.5 \times 1}{(1-1)+0.5}=1.00$

Similarly the GRC for all supplier selection attributes with reference to the remaining five suppliers are computed and are shown in Table 7.

Table 7

Grey relational coefficients for supplier selection attributes

\begin{tabular}{cccccc}
\hline Suppliers & Quality & Price & Delivery & CRP & Service \\
\hline S3 & 0.33 & 0.50 & 1.00 & 1.00 & 1.00 \\
S4 & 0.50 & 1.00 & 0.33 & 0.43 & 0.60 \\
S7 & 0.50 & 0.33 & 0.50 & 1.00 & 0.33 \\
S8 & 0.33 & 1.00 & 0.40 & 0.33 & 1.00 \\
S12 & 0.50 & 0.33 & 0.50 & 1.00 & 1.00 \\
S14 & 1.00 & 0.66 & 0.33 & 1.00 & 0.43 \\
\hline
\end{tabular}

(iii) Calculation of weightages for supplier selection attributes

The priority structure of supplier selection attributes is obtained by using AHP as discussed in step 8 of the section 2.The brainstorming sessions conducted with the purchasing staff of the case company to prepare the pair-wise comparison matrix of supplier selection attributes which is shown in Table 8 .

\section{Table 8}

Pair-wise comparison matrix of the supplier selection attributes

\begin{tabular}{lccccc}
\hline & Quality & CRP & Service & Price & Delivery \\
\hline Quality & 1 & 3 & 2 & 7 & 2 \\
CRP & $1 / 3$ & 1 & 4 & 2 & 3 \\
Service & 0.5 & 0.25 & 1 & $1 / 2$ & $1 / 3$ \\
Price & $1 / 7$ & $1 / 3$ & 2 & 1 & 0.5 \\
Delivery & 0.5 & 0.5 & 3 & 2 & 1 \\
Sum & 2.4728 & 5.25 & 12 & 12.5 & 5.833 \\
\hline
\end{tabular}


The normalized pair-wise comparison matrix is developed by adopting averaging over normalized columns method proposed by Thomas Saaty. The normalized pair-wise comparison matrix is shown in the table 9. The weightages of the supplier selection attributes are obtained and given in the Table 10.

Table 9

Normalized Pair-wise comparison matrix for supplier selection attributes

\begin{tabular}{lcccccc}
\hline & Quality & CRP & Service & Price & Delivery & Sum \\
\hline Quality & 0.4044 & 0.5714 & 0.1667 & 0.5600 & 0.3429 & 2.0454 \\
CRP & 0.1335 & 0.1905 & 0.3330 & 0.1600 & 0.3429 & 1.1601 \\
Service & 0.2022 & 0.0476 & 0.0833 & 0.0400 & 0.0571 & 0.4302 \\
Price & 0.0577 & 0.0952 & 0.1667 & 0.0800 & 0.0857 & 0.4854 \\
Delivery & 0.2022 & 0.0952 & 0.2500 & 0.1600 & 0.1714 & 0.8789 \\
\hline
\end{tabular}

Table 10

Priority structure of the supplier selection attributes

\begin{tabular}{|c|c|c|}
\hline Sl.No & Supplier selection attributes & Weightages \\
\hline 1 & Quality & 0.40907 \\
\hline 2 & Cost Reduction Performance(CRP) & 0.23202 \\
\hline 3 & Service & 0.08604 \\
\hline 4 & Price & 0.09707 \\
\hline 5 & Delivery & 0.17577 \\
\hline
\end{tabular}

In order to check the consistency of pair-wise judgments, the consistency ratio (CR) is computed as discussed in step 8 of section 2 . The value of CR obtained is 0.09911 , which is smaller than 0.10 proved that the AHP results were consistent.

(iv) Determination of grey relational grades $\left(\Gamma_{o i}\right)$ for all the six suppliers.

The grey relational grade for all the suppliers is computed using

$\Gamma_{o i}=\sum_{j=1}^{n}\left[w_{i}(j) \times \gamma_{o i}(j)\right]$

For supplier S3:

$\Gamma_{3}=[(0.40907 \times 0.33)+(0.23202 \times 0.50)+(0.08604 \times 1.00)+(0.09707 \times 1.00)+(0.17577 \times 1.00)]=0.6099$

Similarly GRG for the remaining five suppliers are computed and are summarized in Table 11 . On the basis of grey relational grades, the suppliers are ranked.

Table 11

Grey relational grade for different suppliers

\begin{tabular}{ccccccc}
\hline Suppliers & S3 & S4 & S7 & S8 & S12 & S14 \\
\hline Grey Relational Grade (GRG) & 0.6099 & 0.6102 & 0.4787 & 0.6083 & 0.5960 & 0.7621 \\
Rank of the suppliers & 3 & 2 & 6 & 4 & 5 & 1 \\
\hline
\end{tabular}

According to Grey relational analysis, the alternative which possesses highest grey relational grade is the best choice among all the alternatives. It is observed from the Table 11, the supplier S14 has the highest grey relational grade and hence the S14 is the best supplier for supplying necessary guide rollers to the case company. The company can rely and maintain long-term relationship with the supplier S14 to keep the competitive advantage in the market.

\section{Conclusions}

The ultimate objective of dealing with the supplier selection problem is to identify the best supplier. The selection of best supplier may lead to reduce purchase risk and establish reliable long-term 
relationship between buyers and suppliers. Prior to the selection of the best supplier, it is essential to evaluate the existing suppliers. In the present work, the existing sixteen suppliers are evaluated using super efficiency and cross efficiency methods of DEA. On the basis of super efficiency and crossefficiency scores the suppliers are categorized into a class of six efficient suppliers who possess high performance. The GRA methodology is employed to identify the best supplier among the six suppliers. The proposed DEA-AHP-GRA integrated methodology is well suited to deal with multi-criteria decisions that involve both qualitative and quantitative factors.

\section{Acknowledgement}

The authors express a deep sense of gratitude to the Editor-in-Chief of the "Uncertain Supply Chain Management" and anonymous reviewers for their constructive suggestions that helped to improve the quality of the paper.

\section{References}

Adler, N., Friedman, L., \&Sinuany-Stern, Z. (2002). Review of ranking methods in the data envelopment analysis context. European Journal of Operational Research, 140(2), 249-265.

Burton, T. (1988). JIT/repetitive sourcing strategies: tying the knot with your suppliers. Production and Inventory Management Journal, 29(4), 38-41.

Chang, C. W., Wu, C. R., Lin, C. T., \& Lin, H. L. (2007). Evaluating digital video recorder systems using analytic hierarchy and analytic network processes. Information Sciences, 177(16), 3383-3396.

Prasad, K. G. D., Subbaiah, K.V., Rao, C. V. G., \& Rao, K.N. (2012). Supplier evaluation through data envelopment analysis. Journal of Supply Chain Management Systems, 1(2), 1-11.

Ebadi, S. (2012). Using a super efficiency model for ranking units in DEA. Applied Mathematical Sciences, 6(41), 2043-2048.

Elanchezhian, C., Vijaya Ramnath, B., \& Kesavan, R. (2010). Vendor selection using analytical hierarchy process in supply chain management. Journal of Engineering Research, 1(1), 118-127.

Elanchezhian, C., Ramnath, B. V., \& Kesavan, R. (2010 a). Vendor evaluation using multi criteria decision making technique. International Journal of Computer Applications, 5(9), 4-9.

Handfield, R., Walton, S. V., Sroufe, R., \& Melnyk, S. A. (2002). Applying environmental criteria to supplier assessment: A study in the application of the Analytical Hierarchy Process. European Journal of Operational Research, 141(1), 70-87.

Ho, W., Xu, X., \& Dey, P. K. (2010). Multi-criteria decision making approaches for supplier evaluation and selection: A literature review. European Journal of Operational Research, 202(1), 16-24.

Al-Harbi, K. M. A. S. (2001). Application of the AHP in project management. International Journal of Project Management, 19(1), 19-27.

Ma, R., Yao, L., Jin, M., \& Ren, P. (2014). The DEA game cross-efficiency model for supplier selection problem under competition. Applied Mathematics \& Information Sciences, 8(2), 811-818.

Madhuri, C. B., \& Chandulal, J. A. (2010). Evaluating web sites using COPRAS-GRA combined with grey clustering. International Journal of Engineering Science and Technology, 2(10), 5280-5294.

Malekmohammadi, N., Lotfi, F. H., \& Jaafar, A. B. (2011). Data envelopment scenario analysis with imprecise data. Central European Journal of Operations Research, 19(1), 65-79.

Narasimhan, R., Talluri, S., \& Mendez, D. (2001). Supplier evaluation and rationalization via data envelopment analysis: an empirical examination. Journal of Supply Chain Management, 37(2), 2837.

Nydick, R. L., \& Hill, R. P. (1992). Using the analytic hierarchy process to structure the supplier selection procedure. Journal of Supply Chain Management, 28(2), 31-36.

Pitchipoo, P., Venkumar, P., \& Rajakarunakaran, S. (2012). A distinct decision model for the evaluation and selection of a supplier for a chemical processing industry. International Journal of Production Research, 50(16), 4635-4648. 
Politis, S., Klumpp, M., \& Celebi, D. (2010). Analytical hierarchy process in supplier evaluation. In Proceedings of the 16th International Working Seminar on Production Economics (Vol. 3, pp. 411-424).

Punniyamoorty, M., Mathiyalagan, P., \& Lakshmi, G. (2012). A combined application of structural equation modeling (SEM) and analytic hierarchy process (AHP) in supplier selection. Benchmarking: An International Journal, 19(1), 70-92.

Radfar, R., \& Salahi, F. (2014). Evaluation and ranking of suppliers with fuzzy DEA and PROMETHEE approach. International Journal of Industrial Mathematics, 6(3), 189-197.

Samvedi, A., Jain, V., \& Chan, F. T. (2012). An integrated approach for machine tool selection using fuzzy analytical hierarchy process and grey relational analysis. International Journal of Production Research, 50(12), 3211-3221.

Sepehrdoust, H. (2011). Efficiency measurement of housing sector; using DEA model. In 2011 International Conference on Economics and Finance Research. IPEDR. 4 (2011).

Talluri, S., \& Narasimhan, R. (2004). A methodology for strategic sourcing. European Journal of Operational Research, 154(1), 236-250.

Tahriri, F., Osman, M. R., Ali, A., Yusuff, R. M., \& Esfandiary, A. (2008). AHP approach for supplier evaluation and selection in a steel manufacturing company. Journal of Industrial Engineering and Management, 1(2), 54-76.

Tam, M. C., \& Tummala, V. R. (2001). An application of the AHP in vendor selection of a telecommunications system. Omega, 29(2), 171-182.

Timmerman, E. (1986). An approach to vendor performance evaluation. International Journal of Purchasing and Materials Management, 22(4), 2-8.

Tsinidou, M., Gerogiannis, V., \& Fitsilis, P. (2010). Evaluation of the factors that determine quality in higher education: an empirical study. Quality Assurance in Education, 18(3), 227-244.

Subbaiah,K.V., DurgaPrasad,K.G., Uma Bharathi,M.,\& Rao, K.S.S. (2011). Integrating Factor analysis and Analytic hierarchy process for library service quality. International Journal for Quality Research,5(3), 205-212.

Ventura, J. A., Valdebenito, V. A., \& Golany, B. (2013). A dynamic inventory model with supplier selection in a serial supply chain structure. European Journal of Operational Research, 230(2), 258271.

Wu, T., Shunk, D., Blackhurst, J., \& Appalla, R. (2007). AIDEA: A methodology for supplier evaluation and selection in a supplier-based manufacturing environment. International Journal of Manufacturing Technology and Management, 11(2), 174-192.

Weber, C. A., Current, J. R., \& Benton, W. C. (1991). Vendor selection criteria and methods. European Journal of Operational Research, 50(1), 2-18.

Wei, C., \& Jun-fu, C. (2011). Theoretical discussion of applying grey system theory in neuropsychological studies. Grey Systems: Theory and Application, 1(3), 268-273.

Yang, C. C., \& Chen, B. S. (2006). Supplier selection using combined analytical hierarchy process and grey relational analysis. Journal of Manufacturing Technology Management, 17(7), 926-941.

Yang, J. L., Chiu, H. N., Tzeng, G. H., \& Yeh, R. H. (2008). Vendor selection by integrated fuzzy MCDM techniques with independent and interdependent relationships. Information Sciences, 178(21), 4166-4183.

Zohrehbandian, M., \& Gavgani, S. S. (2013). Cross-efficiency evaluation under the principle of rank priority of DMUs. World Applied Sciences Journal, 21, 46-49.

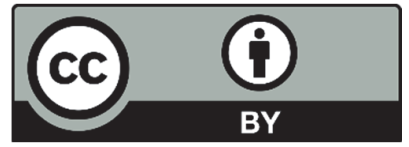

(C) 2017 by the authors; licensee Growing Science, Canada. This is an open access article distributed under the terms and conditions of the Creative Commons Attribution (CC-BY) license (http://creativecommons.org/licenses/by/4.0/). 